\title{
Strength and durability of low-impact environmental self-compacting concrete incorporating waste marble powder
}

\author{
Boukhelkhal A ${ }^{1, *}$, Azzouz L ${ }^{1}$, Benabed B ${ }^{1}$, Belaïdi ASE ${ }^{1}$
}

\author{
1 Civil Engineering Laboratory, University of Laghouat, 03000, Algeria. \\ * Corresponding Author: a.boukhelkhal@lagh-univ.dz
}

\begin{abstract}
This research studies the effect of waste marble powder (WMP) as substitute of Portland cement on strength and durability of self-compacting concrete (SCC) in order to produce SCC with reduced impact environmental. For this purpose, five mixtures were designed in which four mixtures contained WMP at substitution levels of 5, 10, 15, 20\%, and mixture included only the Portland cement as control mix. The realized tests are compressive strength at 3,7 and 28 days, water capillary absorption, water absorption by immersion and sulfate attack. The results show a reduction in the compressive strength with increasing WMP content. The use of WMP was found to increase both of the water capillary absorption and water absorption by immersion. SCC containing WMP subjected to magnesium sulfate attack presented a lower expansion and higher resistance to sulfate aggressions.
\end{abstract}

Key words: self-compacting concrete, waste marble, environment, strength, durability.

\section{Introduction}

Self-compacting concrete (SCC), Self-consolidating concrete, self-leveling concrete, highlyflowable concrete or non-vibrating concrete are very fluid concretes that flow and compact under their proper weight without any effort of compaction or vibration even in highly reinforced structural elements or complex formwork (Naik et al, 2012; Kurita et Nomura, 1998). SCC was appeared and used for the first time in Japan three decades ago, its use was not stopped because SCC has special and interesting properties at fresh state such as flowability, passing ability and resistance to segregation. For achieving these contradictory properties, the formulation of SCC needs the use of high Portland cement content $\left(450-600 \mathrm{~kg} / \mathrm{m}^{3}\right)$ and superplasticizer (SP). However, using high volume of Portland cement causes many problems such as:

- Increase in the consumption of cement

- Environmental impacts due to CO2 emissions

- Consumption of energy and natural resources

- High production cost since the cement is the most expensive element in the concrete

- Risk of cracking associate to the high heat of cement hydration

In order to produce low-impact environmental, economic and durable SCC, the cement is replaced by fine additive materials (FAM) having large proportion of fine particles $(<80 \mu \mathrm{m})$ such as slag, limestone, fly ash, rice husk ash...etc. The reuse of industrial by-products as FAM is a good solution to ensure the equilibrium of eco-system, biological components of the environment and public health (Sadek et al; 2016). Another solution consists in the incorporation of industrial waste materials as fine or coarse aggregates, which can contribute effectively to sustainable development. Using some types of FAM were shown to reduce the 
dosage of SP compared to SCC with only Portland cement. The characteristics of SCC are strongly affected by the type, source, chemical, mineralogical, physical and mechanical properties of FAM. The incorporation of FAM in binary and ternary blended cement improves not only the fresh properties but also the hardened properties of SCC (Sonebi, 2004; Belaidi et al, 2015; Belaidi et al, 2012; Boukhelkhal et al, 2016; Safiuddin, 2008; Uysal et Yilmaz, 2011; Boukhelkhal, 2012; Boukhelkhal et al, 2012). Previous studies found that the use of FAM having different grain-size and morphology enhances the compactness and provides a better workability and cohesiveness by improving the grain-size distribution and particle packing. On other hand, this reduces the risk of cracking associated to the heat of hydration leading therefore to superior performance of SCC at long-term (Sonebi et Bartos, 1999; Boukendakdji et al, 2012). Recycling waste powders of marble and granite in the production of SCC was proved to be useful because the marble powder acts as filler, and granite powder acts as pozzolanic material despite its small pozzolanic activity (Sadek et al, 2016). Benabed et al (2016) have studied the effect of limestone powder as a partial replacement of crushed quarry sand on properties of self-compacting repair mortars, they concluded that the use of limestone powder at substitution rate of 10 to $15 \%$ is beneficial from rheological and strength properties. Research conducted by Chirici et al (2006), was demonstrated that including natural pozzolana (NP) in cement mortars increases the strength at later ages and enhances its resistance to acid and sulfate attacks and chloride ion penetration. Mortars with silica fume (SF), metakaolin (MK) and fly ash (FA) have shown an enhancement in compressive strength, dynamic modulus, ultrasonic pulse velocity, transport properties, sulfate resistance and freezing-thawing resistance (Aghabaglouet al, 2014). Pozzolanic fine additive materials such as SF, MK and FA are characterized by its high specific surface area and pozzolanic reaction in which additional calcium silicate hydrate $\mathrm{CSH}$ forms by reaction between reactive silica and calcium hydroxide produced by the cement hydration.

Marble stone is locally available in some quarries in the East of Algeria and is generally used in buildings for the preparation of slabs and tiles for decorative purposes. However, the process of cutting, shaping and lustrating of the marble stones generates a fine material know as waste marble powder which is not exploited and can pose a serious environmental problems. From this study, an attempt was conducted to produce a reduced impact environmental and durable SCC by exploiting the waste marble powder and investigating its effect as a fine additive materials on the strength and durability properties of SCC.

\section{Experimental procedure}

\subsection{Material properties}

The cement used in this study is an artificial Portland cement (CEMI) class 42.5. Waste marble powder subject of this study is a waste powder resulting from cutting, shaping and lustrating of the marble stones. The chemical composition and physical properties of WMP and cement are given in Table 1. From this table, the WMP is mainly consisted of lime (56.01\%). As fine aggregate (FA), a river sand characterized by granular class of $0 / 5$, and a continuous particles size distribution was used. For coarse aggregate (CA), two classes $3 / 8$ and $8 / 15$ were used. The physical properties of the aggregate are shown in Table 2. The superplasticizer used is a polycarboxylates based High-Range Water Reducers (HRWR). It has a specific gravity and pH of $1.07 \mathrm{~g} / \mathrm{cm}^{3}$ and 8 , respectively. Locally available potable water was used for mixing SCC constituents. 
Table 1. Chemical composition and physical properties of cement and waste marble powder.

\begin{tabular}{|c|c|c|}
\hline Component (\%) & Cement & Waste marble powder \\
\hline $\mathrm{SiO}_{2}$ & 20.14 & 0.42 \\
\hline $\mathrm{CaO}$ & 63.47 & 56.01 \\
\hline $\mathrm{MgO}$ & 2.12 & 0.12 \\
\hline $\mathrm{Al}_{2} \mathrm{O}_{3}$ & 3.71 & 0.13 \\
\hline $\mathrm{Fe}_{2} \mathrm{O}_{3}$ & 4.74 & 0.06 \\
\hline $\mathrm{SO}_{3}$ & 2.67 & 0.01 \\
\hline $\mathrm{K}_{2} \mathrm{O}$ & 0.47 & 0.01 \\
\hline $\mathrm{T}_{\mathrm{i}} \mathrm{O}_{2}$ & 0.21 & 0.01 \\
\hline $\mathrm{Na}_{2} \mathrm{O}$ & 0.69 & 0.43 \\
\hline $\mathrm{P}_{2} \mathrm{O}_{5}$ & 0.06 & 0.03 \\
\hline Loss ignition & 1.72 & 42.78 \\
\hline Density & 3.1 & 2.7 \\
\hline Finesses $\left(\mathrm{cm}^{2} / \mathrm{g}\right)$ & 3300 & 3600 \\
\hline
\end{tabular}

Table 2. Physical properties of aggregates.

\begin{tabular}{|l|c|c|c|}
\hline Aggregate & FA 0/5 & CA 3/8 & CA 8/15 \\
\hline \hline Absorption Coefficient (\%) & 0.59 & 1.56 & 2.26 \\
\hline Density & 2.60 & 2.61 & 2.54 \\
\hline Water content (\%) & 0.03 & 0.17 & 0.13 \\
\hline
\end{tabular}

In order to determine particle size distribution of WMP and cement, laser distribution analysis was realized and the results are illustrated in Figure 1. The results indicate that WMP is relatively finer than the cement, and about $70 \%$ of particles of WMP have a diameter lower them $10 \mu \mathrm{m}$.

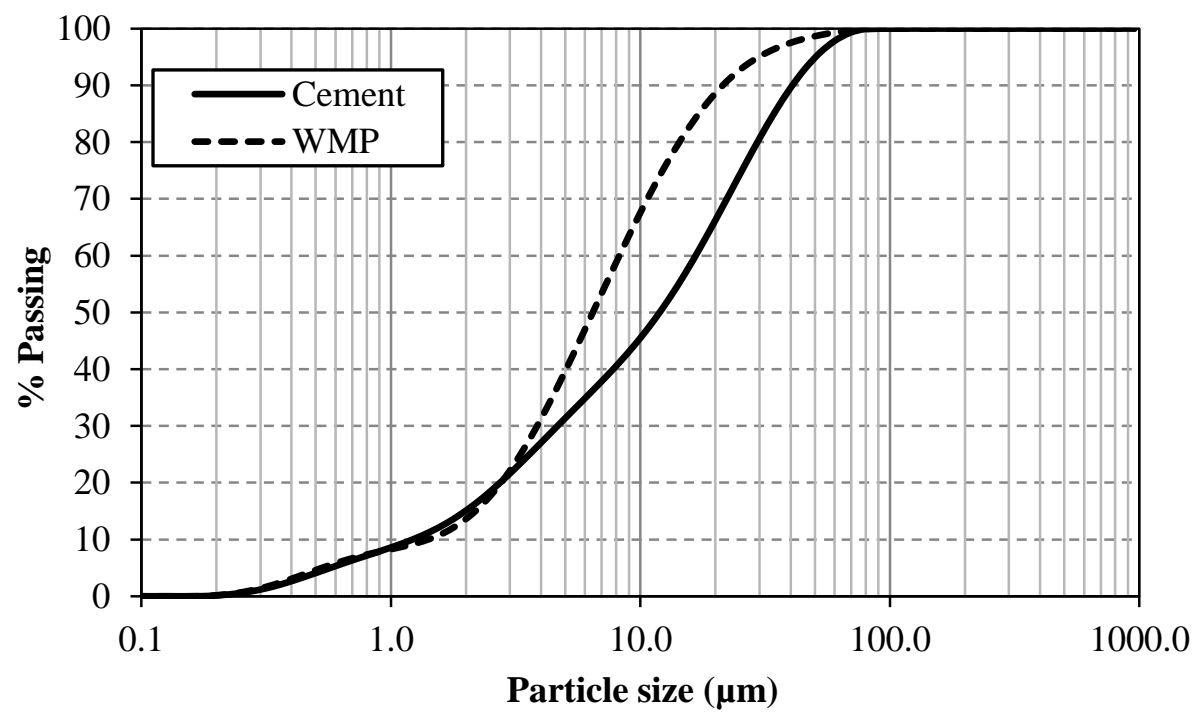

Fig 1. Particle size distribution of cement and waste marble powder.

\subsection{Mix design}

Five mixtures were designed to study the effect of waste marble powder on the strength and durability of SCC. The binder content, water / binder ratio and dosage of superplasticizer were respectively equal to $470 \mathrm{Kg} / \mathrm{m} 3,0.4$ and $0.9 \%$. The control mixture contains only the Portland cement as binder, while other mixtures include the WMP at different substitution levels 5, 10, 15 and $20 \%$. The mix proportions of different mixtures are presented in Table 3. 
Table 3. Mix proportions of SCC.

\begin{tabular}{|c|c|c|c|c|c|}
\hline \multirow{2}{*}{ Materials } & \multicolumn{5}{|l|}{ Mixes } \\
\hline & OWMP & 5WMP & 10WMP & 15WMP & 20WMP \\
\hline Cement (kg) & 470 & 4446.5 & 423 & 399.5 & 376 \\
\hline WMP (\%) & 0 & 5 & 10 & 15 & 20 \\
\hline WMP (kg) & 0 & 23.5 & 47 & 70.5 & 94 \\
\hline Sand $0 / 5(\mathrm{~kg})$ & \multicolumn{5}{|c|}{882.9} \\
\hline Gravel 8/15 (kg) & \multicolumn{5}{|c|}{553} \\
\hline Gravel 3/8 (kg) & \multicolumn{5}{|c|}{277} \\
\hline Water (kg) & \multicolumn{5}{|c|}{188} \\
\hline Superplasticizer (kg) & \multicolumn{5}{|c|}{4.23} \\
\hline $\mathrm{w} / \mathrm{b}$ & \multicolumn{5}{|c|}{0.4} \\
\hline
\end{tabular}

\subsection{Test protocol}

\subsubsection{Compressive strength}

Compressive strength measurements of each mixture were made on six pieces of three prismatic specimens of $70 \times 70 \times 280 \mathrm{~mm}$ size that were previously crushed by flexion. The test was carried out using a hydraulic press with a capacity of $2000 \mathrm{kN}$ at concrete age of 3,7 and 28 days according to the European Standard (EN 12390-3, 2001).

\subsubsection{Water capillarity Absorption}

Water capillary absorption was evaluated on concrete prismatic specimens of $70 \times 70 \times 280 \mathrm{~mm}$ size after initial water-curing of 28 days according to the French standards (NF P 18-502, 1989). The concrete specimens were firstly dried at $105 \pm 5{ }^{\circ} \mathrm{C}$ for 72 hours before being sealed by waterproof material on the sides to ensure one direction of water flow, and stored in water on their cross section with a constant water height of $5 \mathrm{~mm}$. The increase in specimen mass was measured regularly every 5 minutes until 90 minutes. The mass of water absorbed par unit area was plotted against the square root of time. The coefficient of water capillary absorption $\mathrm{C}_{\mathrm{c}}$ is determined using the following equation:

$\frac{\Delta \mathrm{M}}{\mathrm{A}}=\mathrm{C}_{\mathrm{c}} \sqrt{\mathrm{t}}$

Where $\Delta \mathrm{M}$ : mass of water absorbed at time $\mathrm{t}(\mathrm{g})$, A: exposed area of the specimen $\left(\mathrm{cm}^{2}\right), \mathrm{t}$ : elapsed time (min), $\mathrm{C}_{\mathrm{c}}$ : coefficient of water capillary absorption $\left(\mathrm{g} / \mathrm{cm}^{2} / \mathrm{min}^{0.5}\right)$.

\subsubsection{Water Absorption by immersion}

In this test, three concrete prismatic specimens of $70 \times 70 \times 280 \mathrm{~mm}$ size from each mixture were cured in water for 28 days and dried after that at $105 \pm 5{ }^{\circ} \mathrm{C}$ for 72 hours. The specimens were weighed $\mathrm{M}_{0}$ and immediately immersed in water at approximately $21{ }^{\circ} \mathrm{C}$ for not less than 48 hours before being weighed in accordance with ASTM C642-97 (1997). The coefficient of water absorption by immersion $A_{\mathrm{i}}$ is given by the following equation:

$A_{i}=\left(\frac{M_{s}-M_{d}}{M_{d}}\right) \times 100$

Where $M_{s}$ : saturated mass (g), $M_{d}$ : dried mass (g), $A_{i}$ : coefficient of water absorption by immersion (\%). 


\subsection{4 . Sulfate attack}

The sulfate exposure testing procedure was conducted by immersing mortar specimens in sulfate solution after an initial water-curing period of 28 days. $25 \times 25 \times 285 \mathrm{~mm}$ prism and $50 \times 50 \times 50 \mathrm{~mm}$ cube specimens were prepared for sulfate resistance tests. The specimens were immersed in 5\% magnesium sulfate solution at $23 \pm 2{ }^{\circ} \mathrm{C}$ according to ASTM C1012-04 (2004). The solution was renewed every 4 weeks to minimize the increase of $\mathrm{pH}$ due to the leaching $0 \mathrm{H}^{-}$ ions from the mortar specimen. The length changes of prism specimens were measured weekly for the first four months and monthly until six months, for cube specimens, the compressive strength was determined at $0,28,56,90$ and 180 days. The strength gain or loss of the mortar cube specimens was investigated by comparing the strength before immersion ( 0 days) and after immersion $(28,56,90$ and 180$)$ in sulfate solution. Visual control was performed on selected specimens.

\section{Results and discussion}

\subsection{Compressive strength}

Figure 2 shows the evolution of compressive strength with age of testing. The compressive strength of all hardened SCC mixtures increases progressively with curing age. Due to its high volume in Portland cement, the control mix has for all ages the highest values of strength. With the same amount of the binder, the substitution of the cement by the WMP decreases the strength of SCC. The compressive strength of 0WMP; 5WMP; 10WMP; 15WMP and 20WMP mixes at 28 days are $37.2 ; 36.7 ; 34.5 ; 28.8$ and $26.1 \mathrm{MPa}$, respectively. SCC with 5\% of WMP has developed a similar compressive strength with SCC control at 28 days (37 MPa) in comparison with the reference mixture, the compressive strength of 5WMP; 10WMP; 15WMP and 20WMP mixture decreased by $1.3 ; 7.3 ; 22.6 ; 30$ and $36.6 \%$ at 28 days.

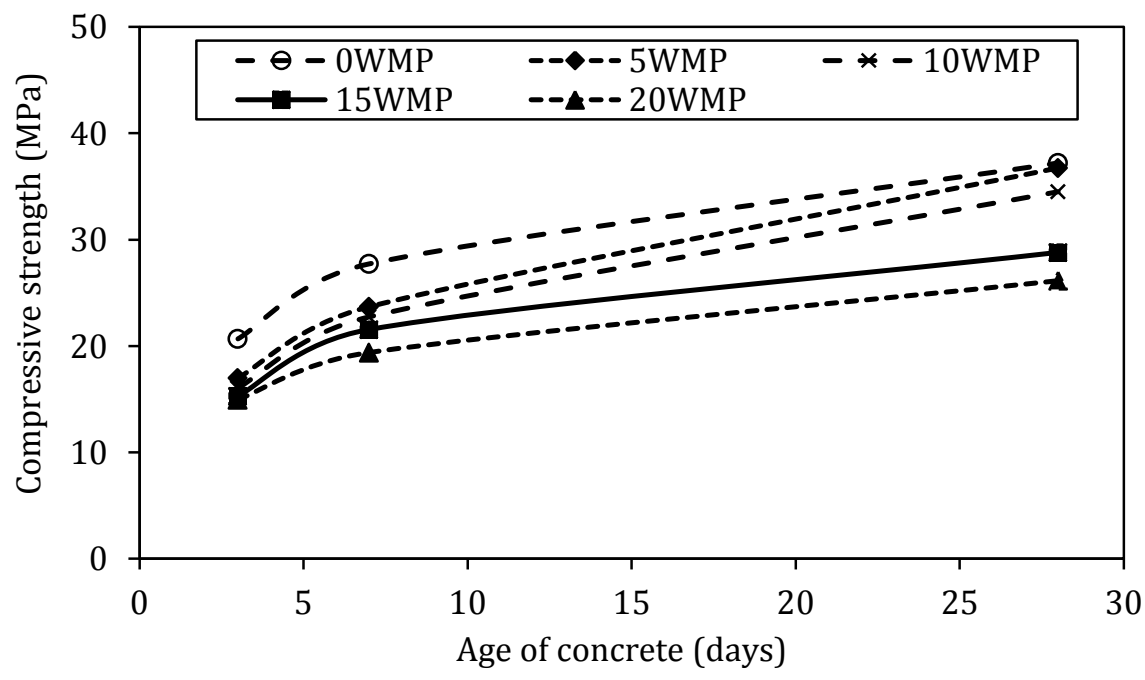

Fig 2. Evolution of compressive strength.

These results are in accordance with those reported by other researchers (Güneyisi et al, 2009; Bouziani et al, 2011). The decrease in compressive strength could be due to the use of a fine inert material having a fineness approximation similar to that of the Portland cement (low filling effect), and to the reduction in the water/cement ratio by adding WMP. In addition, with introducing WMP, the cement paste was insufficient to coat all the sand particles, which consequently leads to a decrease in compressive strength (Benabed et al, 2016). Mixture containing $20 \%$ of WMP and a cement content of about $380 \mathrm{~kg} / \mathrm{m}^{3}$ had developed at 28 days a 
similar compressive strength with ordinary concrete that is generally used in ordinary constructions (26MPa). The replacement of cement and sand by marble powder (MP) at substitution rate of $10 \%$ decreases the compressive strength of mortars, and mortars with MP substituted by sand performed better than mortar with MP substituted by cement (Corinaldesi et al, 2010)

\subsection{Water capillary Absorption}

The influence of WMP on the water capillary absorption is presented in Figure 3. The obtained values show an increase in the water absorption with time for all mixtures. The increase in WMP content increases the water absorption. It should be noted that the reference mixture has the lowest water absorption value, while the water absorption value of mix including $20 \%$ of WMP is the highest. The coefficient of water capillary absorption $\left(\mathrm{C}_{\mathrm{c}}\right)$ of $0 \mathrm{WMP}$; 5WMP; 10WMP; 15WMP and 20WMP mixes are $3.3 \times 10^{-2}, 3.6 \times 10^{-2}, 3.7 \times 10^{-2}, 3.9 \times 10^{-2}$ and $4 \times 10^{-2} \mathrm{~g} / \mathrm{mm}^{2} / \mathrm{min}^{0.5}$. The values demonstrated that increasing WMP content from 5 to $20 \%$ leads to an increase in the coefficient of water capillary absorption from 9.7 to $22.6 \%$. Similar results were obtained in concrete containing slag at substitution levels of 15,30 and $50 \%$, with $\mathrm{w} / \mathrm{b}$ ratio of 0.65 , tested at 28 days (Hadjsadoka et al, 2012).

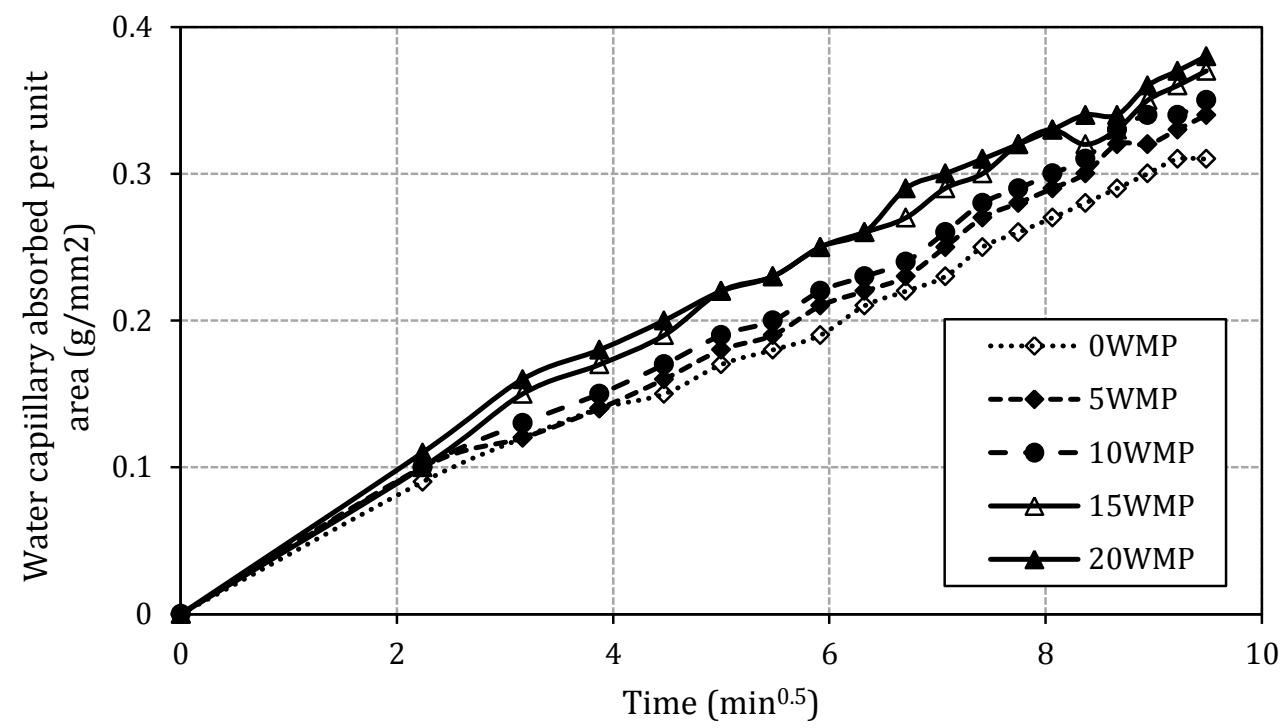

Fig 3. Effect of waste marble powder on water capillary absorption.

\subsection{Water Absorption by immersion}

The durability of concretes is significantly influenced by their pore structure. This parameter can be evaluated by measuring water Absorption by immersion. The variation of water absorption by immersion for all SCC mixes is illustrated in Figure 4. It is clear from the obtained results that the increase in the amount of substituted WMP leads to an increase in the water absorption. The water absorption values of mixtures containing $0,5,10,15$ and 20\% of WMP are 4.67; 5.10; 5.11; 5.13 and $5.17 \%$, respectively. This means that incorporation of WMP at substitution levels of 5, 10,15 and $20 \%$ increases the water absorption rate by $9.26,9.47,9.9$ and $10.9 \%$, respectively. It was noted that all tested SCC have low water absorption (less than 10\%) (Siddique, 2013), exception for mix that including 20\% of WMP. In other hand, the obtained water absorption values are superiors to those found in mortar mixtures incorporated fly ash, silica fume and metakaolin (1.8 to $4.2 \%$ ). These may be attributed to the use of inert material that having a low 
filling effect because both the cement and WMP have approximately similar fineness (Aghabaglouet al, 2014). Similar effects was observed in SCC made bottom ash in which increasing the amount of bottom ash increases water absorption by immersion (Siddique, 2013).

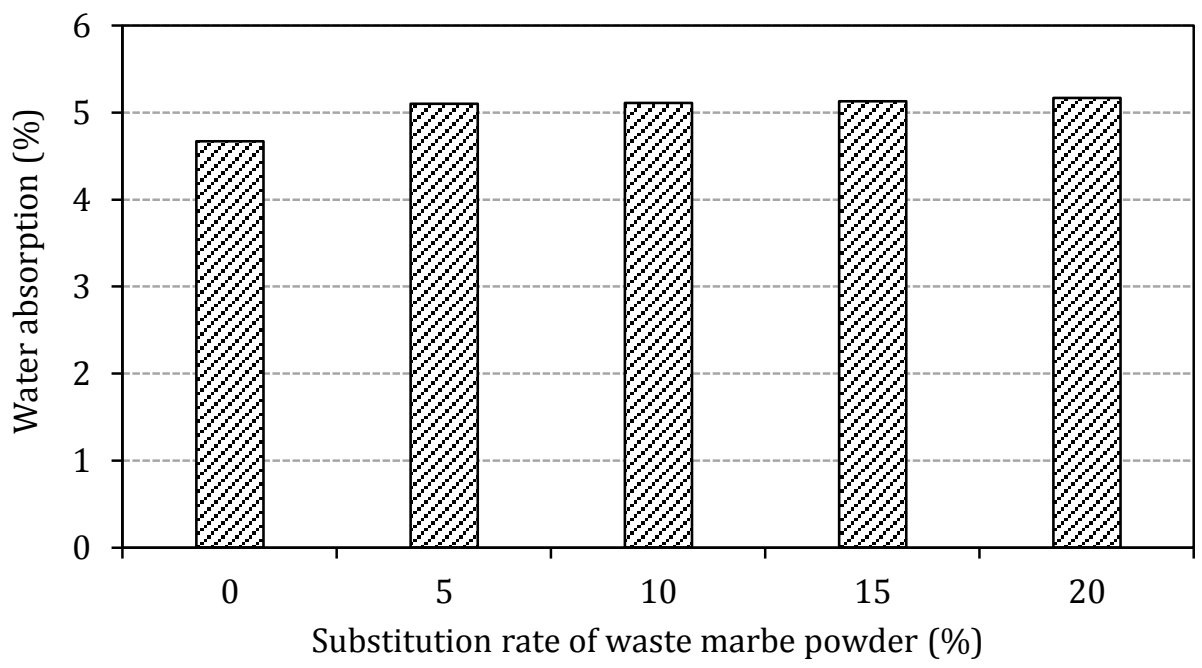

Fig 4. Variation of water absorption versus the substitution rate of waste marble powder.

\subsection{Correlation between compressive strength and water absorption by immersion}

Correlation between compressive strength and water absorption by immersion is illustrated in figure 5. Compressive strength decreases with increasing water absorption by immersion. It can be noted that there is a moderate linear relationship between these parameters. The coefficient of correlation was equal to 0.37 . This relation suggests that with the increase in water absorption by immersion, SCC is expected to have reduced compressive strength.

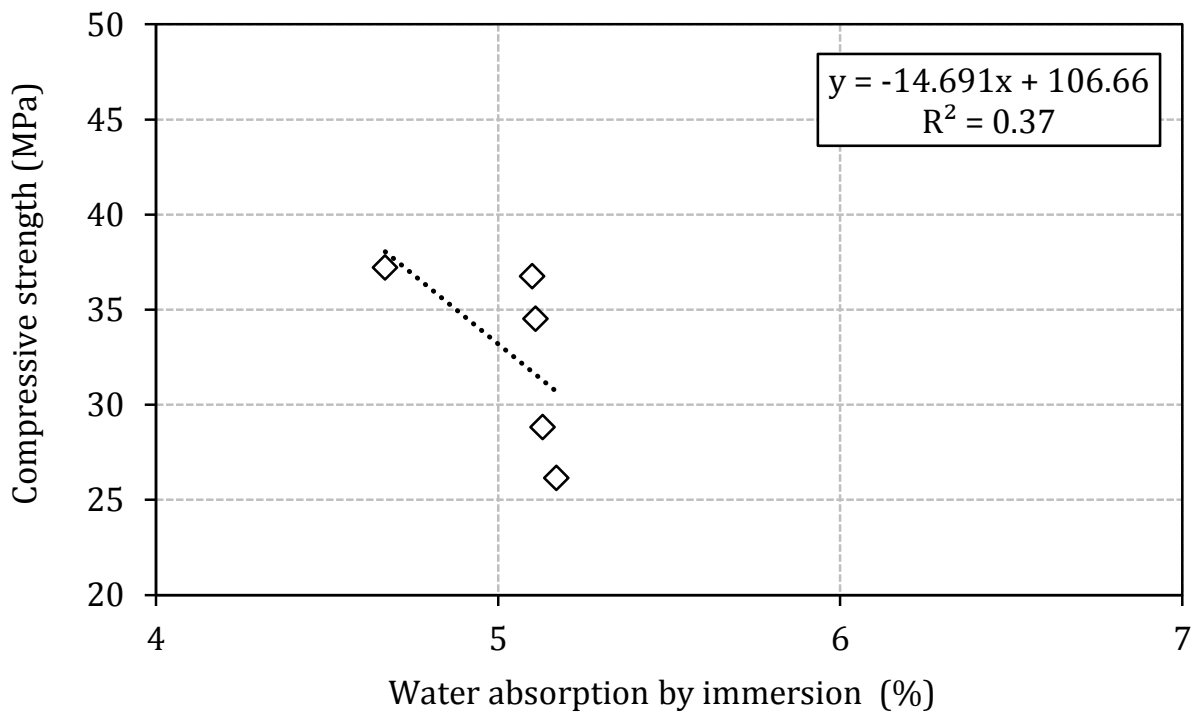

Fig 5. Correlation between compressive strength at 28 days and water absorption by immersion.

\subsection{Correlation between compressive strength and water capillary absorption}

Figure 6 presents the correlation between compressive strength at 28 days and coefficient of water capillary absorption of various SCC mixtures. It is clear from the obtained results that the decrease in compressive strength is associated to the decrease of the water capillary absorption 
coefficient. The results indicate that there is an excellent relationship between these parameters. The coefficient of correlation was found to be close to 1 .

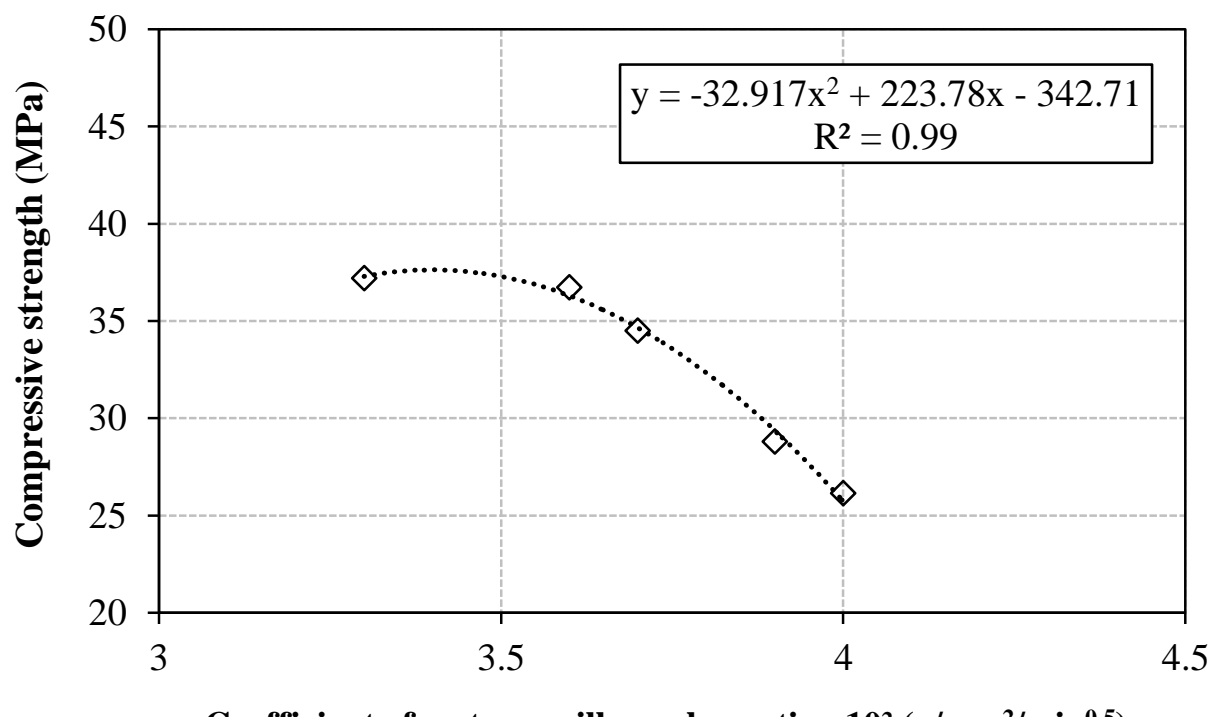

Coefficient of water capillary absorption $10^{2}\left(\mathrm{~g} / \mathrm{mm}^{2} / \mathrm{min}^{0.5}\right)$

Fig 6. Correlation between compressive strength at 28 days and coefficient of water capillary absorption.

\subsection{Effects of sulfate attack}

\subsubsection{Expansion}

Figure 7 depicts the evolution of the expansion of mortars with and without WMP. The expansion increases with increase of the immersion period in sulfate solution. It had been observed that there is an inversely proportional relation between the increase in WMP volume and the decrease in the expansion.

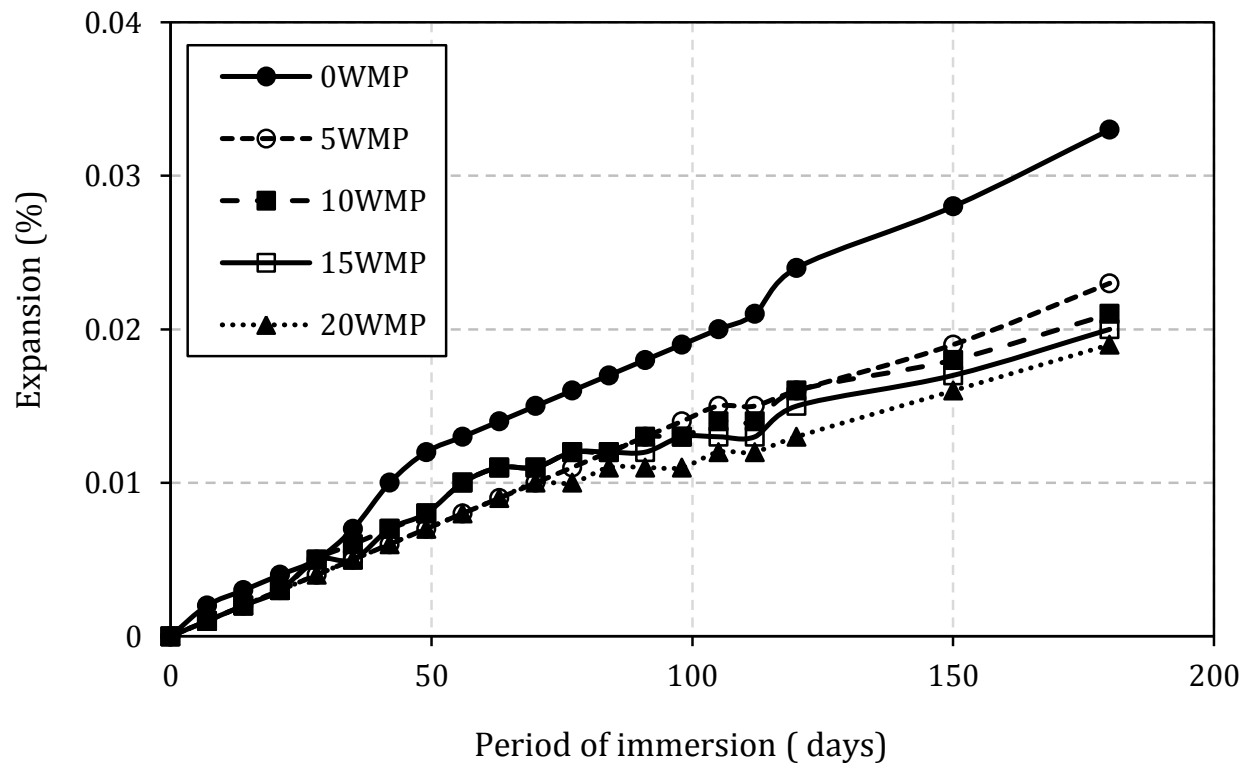

Fig 7. Evolution of the expansion of mortar specimens immersed in magnesium sulfate solution.

The results showed that the mix without WMP has the highest values of expansion, whereas the mix with $20 \%$ of WMP showed the lowest values of expansion. At 180 days, the expansion values of 0WMP, 5WMP, 10WMP, 15WMP and 20WMP mixes are $3.3 \times 10^{-2}, 2.3 \times 10^{-2}, 2.1 \times 10^{-2}, 2 \times 10^{-2}$ and 
$1.9 \times 10^{-2} \%$. This means that the incorporation of WMP at substitution rate of 5, 10, 15 and $20 \%$ decreased the expansion by $30,36,39$ and $42 \%$, respectively. The increase in the expansion for all mixes is attributed to the formation of two voluminous products (gypsum and ettringite). The decrease in the expansion for mortars with WMP compared to mortar with plain cement is due to the reduction in the cement content which reduces the $\mathrm{C}_{3} \mathrm{~A}$ content in the binder and the volume of the ettringite product (Aghabaglouet al, 2014).

\subsubsection{Compressive strength}

Figure 8 presents the evolution of the compressive strength of mixtures with and without WMP as a function to the period of immersion in magnesium sulfate solution. It can be seen from this figure that the reference mix shows a strength gain of about $24 \%$ at immersion period of 28 days. However, after this period the strength gain slightly decreases at immersion period of 56 and 90 days (18 and 17\%), but considerably decreases at 180 days (1\%). For mixes containing WMP, the strength gain increases until 180 days. The strength gain of 5WMP, 10WMP, 15WMP and 20WMP mixes is about 13,26, 28 and $21 \%$ for immersion period of 28, 56, 90 and 180 days, respectively. This demonstrates that the inclusion of $10 \%$ of WMP by partial replacement of the cement is considered the optimum substitution rate. The strength gain might be attributed to the continuous hydration of anhydrated cement products and the reaction of $\mathrm{MgSO}_{4}$ with $\mathrm{Ca}(\mathrm{OH})_{2}$ to form two voluminous elements (gypsum and ettringite) which fill in the micro-pores leading to a denser structure. The reduction in strength gain is due to the expansion effect of the sulfate attack which leads to the formation of micro-cracks and softening of the cement matrix (Ghrici et al, 2006).

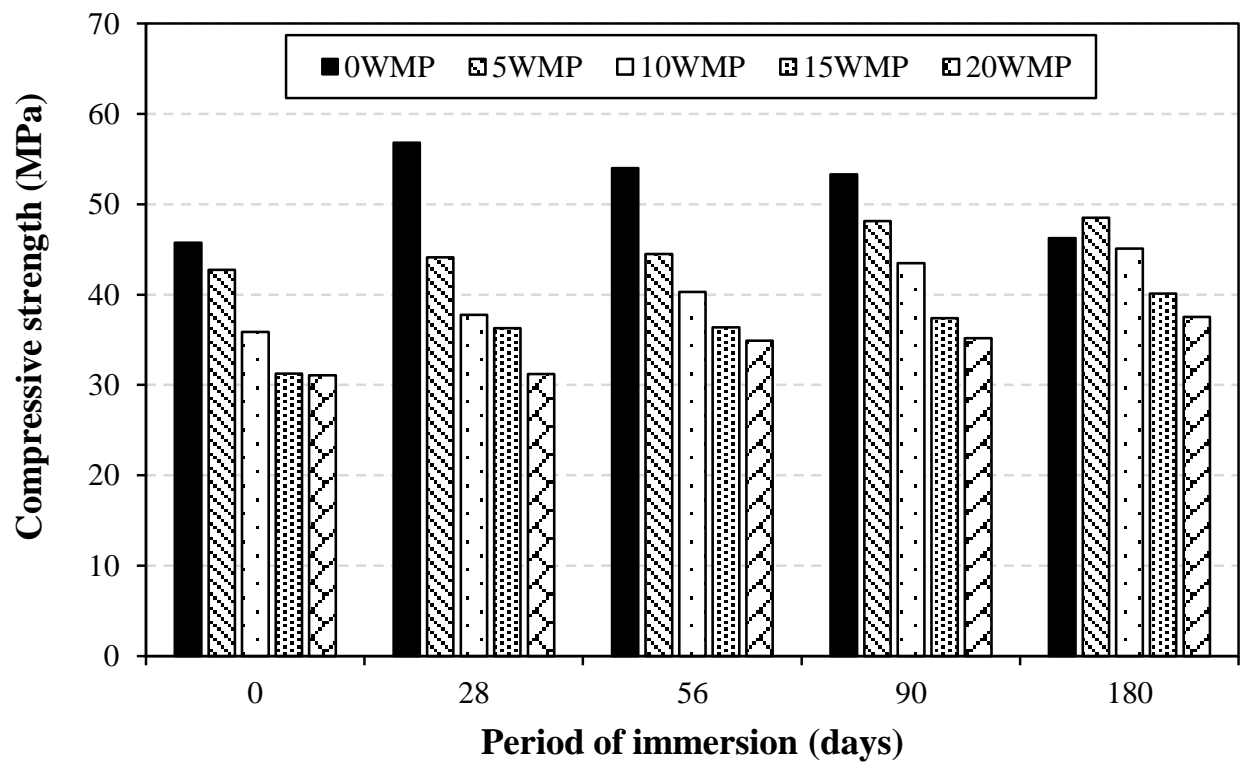

Fig 8. Evolution of compressive strength of mortar specimens immersed in magnesium sulfate solution.

\subsubsection{Visual control}

Visual inspection on some selecting mortar specimens was carried out after 180 days of immersion in the magnesium sulfate solution to evaluate the visible signs of softening, cracking and spalling in the mortar specimens, the results are shown in Figure 9. From this control, a low spalling deterioration was observed especially at the edges and corners of some specimens, in particular those of the control mortar. This is due to the fact that these places are exposed to two (edges) or three (corners) penetration flux of sulfate ions, which accelerates their degradation. 

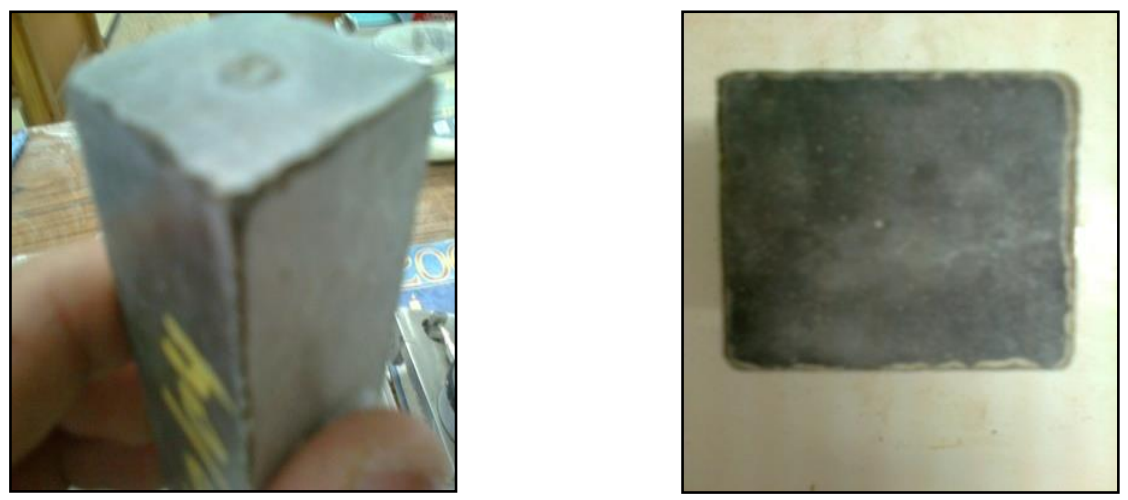

Fig 9. Visual control of mortar specimens.

\section{Conclusions}

This investigation was conducted to assess the strength and durability of reduced environmental impact SCC made with waste marble powder. From the obtained results in this investigation, the following conclusions can be drawn:

- SCC made with waste marble powder at replacement level of 5\% developed approximately similar compressive strength with control SCC. At 28 days, compressive strength values ranging from 26 to $37 \mathrm{MPa}$ were obtained. These results allow the use of different replacement levels of WMP for different concrete purposes. For example, SCC containing WMP content of $10 \%$ can be used in a structure when the desired strength is about $35 \mathrm{MPa}$.

- Concerning the water capillary absorption and water absorption by immersion, a slight increase in amount of water absorbed was observed when the cement is partially replaced by WMP.

- Correlations between compressive strength at 28 days and water absorption properties were found very good with a coefficient of correlation more than 0.9 .

- Incorporating WMP in SCC mixes immersed in magnesium sulfate solution was found to decrease the expansion and to improve the resistance to sulfate aggressions.

- Finally, it can be concluded that the exploitation of waste marble powder as fine materials in production of SCC is very advantageous from technical, economical and environmental points of view.

\section{References}

Aghabaglou AM, Sezer GI, Ramyar K. (2014). Comparison of fly ash, silica fume and metakaolin from mechanical properties and durability performance of mortar mixtures view point. Construction and Building Materials, 70, 17-25.

ASTM C 642-97. (1997). Standard test method for density, absorption, and voids in hardened concrete. American Society for Testing and Materials, USA.

ASTM C 1012-04. (2004). Standard test method for length change of hydraulic cement mortar exposed to a sulfate solution. American Society for Testing and Materials, USA.

Belaidi ASE, Kenai S, Kadri EH, Soualhi H, Benabed B. (2015). Effects of experimental ternary cements on fresh and hardened properties of self-compacting concretes. Journal of Adhesion Science and Technology, 30, 247-261.

Belaidi ASE, Azzouz L , Kadri E, Kenai S. (2012). Effect of natural pozzolana and marble powder on the properties of self-compacting concrete. Construction and Building Materials, 31, 251-257.

Boukhelkhal A, Azzouz L, Belaïdi ASE, Benabed B. (2016). Effects of marble powder as a partial replacement of cement on some engineering properties of self compacting concrete. Journal of Adhesion Science and Technology, 30(22), 2405-2419.

Boukhelkhal A. (2012). Rheology, physical and mechanical characterization and durability of selfcompacting concrete made with marble powder. [MSc thesis]. University of Laghouat, Algeria. p.170. 
Boukhelkhal A, Azzouz L, Belaïdi ASE, Benabed B. (2012). Effect of marble powder on the properties of self-compacting concrete at fresh state. In: Proceeding of First International international conference on civil engineering, Laghouat, Algeria.

Boukendakdji O, Kadri EH, Kenai S. (2012). Effects of granulated blast furnace salg and superplastizer type on the fresh properties and compressive strength of self-compacting concrete. Cement and Concrete Composites, 34(4), 583-590.

Benabed B, Soualhi H, Belaidi ASE, Azzouz L, Kadri E, Kenai S. (2016). Effect of limestone powder as a partial replacement of crushed quarry sand on properties of self-compacting repair mortars. Journal of Building Materials and Structures, 3,15-30.

Bouziani T, Benmounah A, Bederina M, Lamara M. (2011). Effect of marble powder on the properties of self-compacting sand concrete. The Open Construction \& Building Technology Journal, 5, 25-29.

Corinaldesi V, Moriconia G, R. Naik T. (2010). Characterization of marble powder for its use in mortar and concrete. Construction and Building Materials, 24(1), 113-117.

EN 12390-3. (2001). Testing hardened concrete - Part 3: Compressive strength of test specimens. European committee for standardization, Bruxelles.

Ghrici M, Kenai S, Meziane E. (2006). Mechanical and durability properties of cement mortar with Algerian natural pozzolana. Materials Science, 41(21), 6965-6972.

Güneyisi E, Gesoğlu M, Özbay E. (2009). Effects of marble powder and slag on the properties of selfcompacting mortars. Materials and Structures, 42, 813-826.

Hadjsadoka A, Kenai S, Courard L, Michel F, Khatib J. (2012). Durability of mortar and concretes containing slag with low hydraulic activity. Cement and Concrete Compsites, 34(5), 671-7.

Kurita M, Nomura T. (1998). High-flowable steel fiber-reinforced concrete containing fly ash. In: Malhotra VM, editor. Proceedings, sixth CANMET/ACI international conference on fly ash, silica fume, slag, and natural Pozzolans in concrete, SP-178. Farmington Hills, MI: American Concrete Institute. p. 159-179.

Naik R.T, Kumara R, W. Rammeb B, Canpolatc F. (2012). Development of high-strength, economical selfconsolidating concrete. Construction and Building Materials, 30, 463-469.

NF P 18-502 (1989). Water capillary absorption. Paris: AFNOR.

Sadek DM, El-Attar MM, Haitham AA. (2016). Reusing of marble and granite powders in self-compacting concrete for sustainable development. Cleaner Production, 121, 19-32.

Sonebi M. (2004). Medieum strength self-compacting concrete containing fly ash: modeling using factorial experimental plans. Cement and Concrete Research, 34(7), 1199-1208.

Safiuddin M. Development of self-consolidating high performance concrete incorporating rice husk ash. (2008). Phd thesis, University of Waterloo, Canada, p.359

Sonebi M, Bartos PJ. (1999, September). Hardened SCC and its bond with reinforcement. In: Proceeding of First International RILEM Symposium on Self-Compacting Concrete (PRO 7), Stockholm, Sweden.

Siddique R. (2013). Compressive strength, water absorption, sorptivity, abrasion resistance and permeability of self-compacting concrete containing coal bottom ash. Construction and Building Materials, 47, 1444-1450.

Uysal M, Yilmaz K. Effect of mineral admixtures on properties of self-compacting concrete. (2011). Cement and Concrete Composites, 33, 771-776. 